\title{
Erratum to: Extremely Preterm Born Children at Very High Risk for Developing Autism Spectrum Disorder
}

\author{
Liedewij Verhaeghe $^{1} \cdot$ Mieke Dereu $^{1} \cdot$ Petra Warreyn $^{1} \cdot$ Isabel De Groote $^{2}$. \\ Piet Vanhaesebrouck ${ }^{3} \cdot$ Herbert Roeyers $^{1}$
}

Published online: 30 April 2016

(C) Springer Science+Business Media New York 2016

\section{Erratum to: Child Psychiatry Hum Dev DOI 10.1007/s10578-015-0606-3}

The original version of this article unfortunately contained mistakes. In the "Methods" section on page 2, right column, lines 3 and 15, the words "cerebellar haemorrhage" should read as "cerebral hemorrhages". The authors regret the inconvenience caused to the readers in this regard.

The online version of the original article can be found under doi:10.1007/s10578-015-0606-3.

Liedewij Verhaeghe

liedewij.verhaeghe@ugent.be

1 Department of Experimental Clinical and Health Psychology, Ghent University, Henri Dunantlaan 2, 9000 Ghent, Belgium

2 Department of Child and Adolescent Psychiatry, University Hospital Ghent, Ghent, Belgium

3 Department of Neonatal Intensive Care, University Hospital Ghent, Ghent, Belgium 